CONCISE REPORT

\title{
Methotrexate treatment in juvenile idiopathic arthritis: when is the right time to stop?
}

\author{
D Foell, M Frosch, A Schulze zur Wiesch, T Vogl, C Sorg, J Roth
}

Objectives: To investigate whether prolonged methotrexate (MTX) treatment after induction of remission influences the subsequent duration of remission in patients with juvenile idiopathic arthritis (JIA), and to analyse the usefulness of myeloid related proteins 8 and 14 (MRP8/MRP14) as predictive markers for the stability of remission at the time when MTX is withdrawn.

Methods: Twenty five patients with oligoarticular and polyarticular JIA who received MTX to induce remission were followed up. MTX treatment was stopped after a mean of 3.8 months (group 1) or 12.6 months (group 2) after remission was documented. Differences in the number of relapses between these groups were looked for. Additionally, MRP8/MRP14 were analysed by ELISA in 22 patients.

Results: No difference was found in the number of relapses between patients with prolonged or early discontinued MTX treatment. Patients who were in stable remission had significantly lower MRP levels when MTX was discontinued than patients with relapses. With a cut off point for MRP8/ MRP1 4 at $250 \mathrm{ng} / \mathrm{ml}$, sensitivity and specificity were $100 \%$ and $70 \%$, respectively.

Conclusion: Longer duration of MTX treatment after induction of remission does not generally improve the status of remission in patients with JIA. Residual synovial inflammation seems to influence the rate of relapses after discontinuation of MTX treatment. MRP8/MRP14 indicate residual activity even in the absence of other laboratory or clinical signs of continuing inflammation. Normal serum concentrations of MRP8/MRP1 4 in clinical inactive arthritis may help to identify patients in whom MTX can be safely withdrawn after remission is achieved.

M ethotrexate (MTX) is accepted to be an efficient treatment for juvenile idiopathic arthritis (JIA). Remission can be induced in most patients using combined anti-inflammatory treatment. ${ }^{23}$ About half of the patients have relapses or flares after discontinuation or reduction of MTX. Therefore, continuation of MTX for 1224 months after induction of remission has been proposed, ${ }^{45}$ although no controlled prospective studies have been performed to investigate the impact of early discontinuation of MTX treatment on the duration of remission and the rate of relapses. It is important to know when it is safe to withdraw immunosuppressive drugs like MTX or tumour necrosis factor $\alpha$ blocking agents because of their potentially serious side effects. It would be unnecessary to continue these drugs in patients who are in stable and frequently lifelong remission. The rate of relapses may be influenced by residual synovial inflammation at the time when MTX is withdrawn. Unfortunately, reliable serum markers to detect such non-apparent disease activity are lacking.
To date, we have no means of identifying those clinically inactive patients at special risk for relapses. Definition of disease activity in JIA is exclusively based on clinical or routine laboratory measures. ${ }^{6-9}$ On the other hand, the rate of relapses in JIA after reduction of immunosuppressive treatment during clinical remission is high. Thus, it would be helpful to define more sensitive markers for determining the risk of remitting arthritis in JIA. Myeloid related proteins (MRP) 8 (S100A8) and 14 (S100A9) are expressed by early recruited monocytes and granulocytes. They are calcium binding proteins assembling to heterodimers. MRP8/MRP14 are secreted by infiltrating phagocytes in synovial inflammation. $^{10}$ Serum concentrations of these proteins correlate sensitively and specifically with synovial inflammation in JIA. ${ }^{11}$

In this study we analysed clinical and laboratory parameters in 25 patients with JIA in a prospective follow up study to evaluate the impact of the duration of MTX treatment in remission on the rate of relapses. In order to differentiate patients at special risk for relapse we examined MRP8/ MRPI4 serum concentrations.

\section{PATIENTS AND METHODS \\ Patients}

We performed a prospective study including 25 children who fulfilled the criteria for JIA with an oligoarticular or polyarticular course of the disease. ${ }^{12}{ }^{13}$ At study entry all patients had clinical symptoms of active arthritis, as defined previously. ${ }^{7}$ All patients received MTX $\left(10 \mathrm{mg} / \mathrm{m}^{2}\right.$ body surface area) to induce remission. MTX treatment was stopped earlier than six months (group 1, 15 patients) or later than six months (group 2, 10 patients) after remission according to American College of Rheumatology (ACR) criteria had been documented. Patients were followed up over 12-36 months at intervals of 12 weeks after MTX was stopped. Table 1 summarises the characteristics of patients.

\section{Documentation of clinical parameters}

Disease activity was documented by the doctor's global assessment and patient's/parental assessment of disease activity, determination of functional ability, and the number of active joints (joint swelling or limitation of movement, with either pain on movement or tenderness). Patients were categorised as having active disease, or were considered to be in remission based on the ACR criteria ${ }^{6}$ for at least three consecutive months, including duration of morning stiffness not exceeding 15 minutes, no fatigue, no active arthritis, and an erythrocyte sedimentation rate (ESR) $<20 \mathrm{~mm} / \mathrm{lst}$ h.

\footnotetext{
Abbreviations: ACR, American College of Rheumatology; CRP, C reactive protein; ELISA, enzyme linked immunosorbent assay; ESR, erythrocyte sedimentation rate; JIA, juvenile idiopathic arthritis; MRP, myeloid related protein; MTX, methotrexate
} 


\begin{tabular}{|c|c|c|}
\hline \multirow[b]{2}{*}{ Discontinuation of MTX } & \multicolumn{2}{|l|}{ Groups } \\
\hline & Early & Late \\
\hline Number of patients & 15 & 10 \\
\hline $\begin{array}{l}\text { Diagnosis (oligoarticular/polyarticular } \\
\text { JIA) }\end{array}$ & $7 / 8$ & $5 / 5$ \\
\hline Sex (female/male) & $13 / 2$ & $8 / 2$ \\
\hline Age (years), mean (range) & $6.6(3-12)$ & $6.0(4-11)$ \\
\hline MTX $\left(\mathrm{mg} / \mathrm{m}^{2}\right)$, mean (range) & $9.9(5-15)$ & $10.2(5-15)$ \\
\hline $\begin{array}{l}\text { MTX continuation* (months), mean } \\
\text { (range) }\end{array}$ & $3.8(0-6)$ & $12.6(7-18)$ \\
\hline Tapering before stop, № (\%) & $11(73)$ & $4(40)$ \\
\hline Relapses, No (\%) & $7(47)$ & $6(60)$ \\
\hline $\begin{array}{l}\text { Duration of remission (months), mean } \\
\text { (range) }\end{array}$ & $14.9(3-36)$ & $12.1(1-36)$ \\
\hline MRP active (ng/ml), mean (SEM) & $2970(1070)$ & 2920 (970) \\
\hline MRP in remission $(\mathrm{ng} / \mathrm{ml})$, mean (SEM) & $490(80)$ & $420(80)$ \\
\hline CRP active $(\mathrm{mg} / \mathrm{l})$, mean (SEM) & $19(9)$ & $23(7)$ \\
\hline CRP in remission (mg/l), mean (SEM) & 1 (1) & 1 (1) \\
\hline ESR active $(\mathrm{mm} / 1 \mathrm{st} \mathrm{h})$, mean (SEM) & $26.5(4.5)$ & $26.9(5.6)$ \\
\hline $\begin{array}{l}\text { ESR in remission }(\mathrm{mm} / 1 \mathrm{st} \mathrm{h}) \text {, mean } \\
\text { (SEM) }\end{array}$ & $9.3(1.1)$ & $12.6(2.6)$ \\
\hline $\begin{array}{l}\text { Active joints (maximally active), mean } \\
\text { (range) }\end{array}$ & $3.1(1-8)$ & $5(2-13)$ \\
\hline
\end{tabular}

\section{Laboratory examinations}

Serum concentrations of MRP8/MRP14 were determined by a sandwich enzyme linked immunosorbent assay (ELISA) following the system established in our laboratory. ${ }^{11}$ MRP8/ MRP14 serum levels of 22 patients were analysed in active disease before starting MTX, and also in remission at the time when treatment with MTX was stopped. In the remaining three patients no serum was obtained at this time. ESR (Westergren method) and C reactive protein (CRP; nephelometry) were analysed at each time point of this study.

\section{Statistical analysis}

Mann-Whitney U test was performed to analyse differences between the groups of patients. Data are given as the mean (SEM) unless otherwise indicated. Receiver operating curves were employed to analyse the diagnostic value of MRP8/ MRP14 serum levels. ${ }^{14}{ }^{15}$ This method has been proposed for analysing the diagnostic value and accuracy of immunological tests in rheumatic disorders. It allows calculation of sensitivity, specificity, and likelihood ratio over a broad range for tested variables. In addition, survival and log rank analyses were performed to study the rate of relapses and the duration of remission in groups of patients.

\section{RESULTS}

\section{Relapses after discontinuation of MTX treatment}

Thirteen (52\%) patients had a relapse of JIA within two years after treatment with MTX was stopped. There was no difference between patients with oligoarticular or polyarticular JIA.

\section{Influence of the time of MTX withdrawal on the rate of relapses}

We found no difference in the duration of remission and the number of relapses between patients with prolonged or early discontinued MTX treatment. Seven patients (47\%) had a relapse in group 1 (early withdrawal), while six patients $(60 \%)$ relapsed in group 2 (late withdrawal). Within the first year after stopping MTX, the flare up rate was 33\% in group 1 , compared with $60 \%$ in group 2 . A log rank analysis for the whole follow up period showed no significant difference for

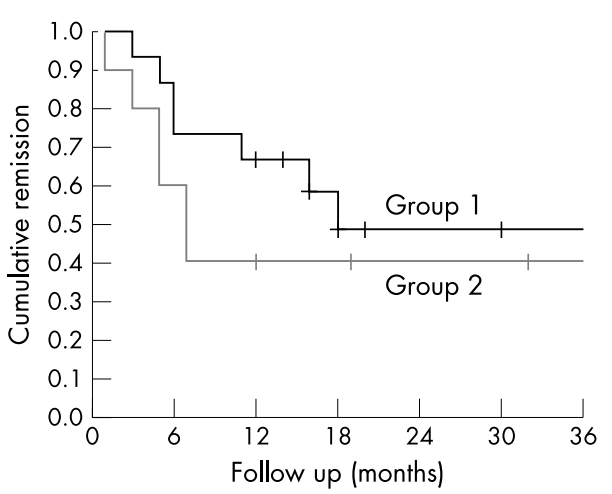

Figure 1 Duration of remission. A survival analysis showed that patients after early discontinuation of MTX (group 1) had neither earlier flare ups nor more relapses than patients with late discontinuation (group 2). Point $O$ indicates the time when MTX was withdrawn. Ticks in the graphs for both groups indicate censored data for patients with subsequent follow up of $<36$ months. A log rank analysis confirmed that the difference between both groups was not significant $(p=0.35)$.

the duration of remission between the groups (0.87; $\mathrm{p}=0.35$ ). Figure 1 shows the survival analysis.

\section{Serum concentrations of MRP 8 /MRP 14}

Significant reduction of MRP8/MRP14 serum concentrations in response to MTX treatment was found (fig 2A). Mean (SEM) MRP8/MRP14 serum levels in active disease before the start of MTX treatment were 2970 (1070) ng/ml in group 1 and 2920 (970) ng/ml in group 2. Mean MRP8/MRP14 serum levels in inactive disease after successful MTX treatment were $490(80) \mathrm{ng} / \mathrm{ml}$ in group $\mathrm{l}$ and 420 (80) ng/ $\mathrm{ml}$ in group 2.

\section{Predictive value of MRP levels for the risk of relapse} Patients who were in stable remission for at least one year after MTX was stopped had significantly lower MRP levels when MTX was discontinued than patients who had a relapse within one year (mean (SEM) 210 (30) ng/ml v 590 (90) ng/ml;
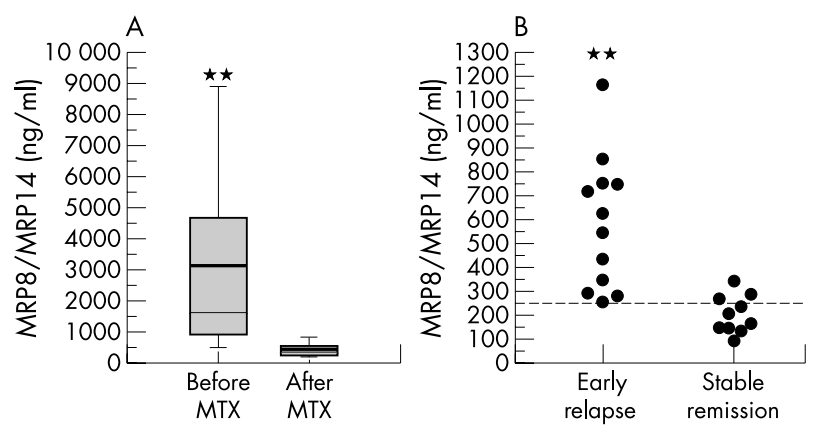

Figure 2 Serum levels of MRP8/MRP14. (A) MRP8/MRP14 concentrations were analysed in 22 patients with oligoarticular and polyarticular JIA before and after the start of MTX treatment. There was a significant difference between serum concentrations in active disease before starting treatment with MTX and in inactive disease after successful treatment, respectively. Box plots show median, mean (bold line), 25th and 75th centiles. Error bars indicate 5th and 95th centiles $\left({ }^{* *} p<0.001\right)$. (B) MRP8/MRP1 4 concentrations were analysed in serum from patients in remission, obtained at the time when MTX treatment was stopped. Two groups of patients were compared according to their outcome within one year after withdrawal of MTX. Serum levels were significantly higher in patients who had a relapse within the following year than in patients who stayed in stable remission. Data points show individual MRP8/MRP14 serum concentrations. The dashed line indicates a cut off point at $250 \mathrm{ng} / \mathrm{ml}$ with a sensitivity to detect risk for a relapse of $100 \%$, while specificity was $70 \%\left({ }^{* *} p<0.01\right)$. 
$\mathrm{p}<0.01$ ). Figure $2 \mathrm{~B}$ shows data for individual patients. ESR and CRP showed no difference (data not shown). With a cut off point for MRP8/MRP14 at $250 \mathrm{ng} / \mathrm{ml}$, sensitivity and specificity were $100 \%$ and $70 \%$ for detecting a special risk for relapse, respectively. With a cut off point at $270 \mathrm{ng} / \mathrm{ml}$ sensitivity was $92 \%$, with a specificity of $80 \%$ (positive likelihood ratio 4.6). Receiver operating curve analyses strongly suggested a diagnostic value for the risk of relapse (area under curve 0.95 , 95\% confidence interval 0.85 to $1.00 ; \mathrm{p}<0.001$ ), although these results have to be interpreted with care owing to the small number of patients included.

\section{DISCUSSION}

Our data confirm the problem of a high relapse rate after withdrawal of MTX. Taken together, 13 of our 25 patients (52\%) had a relapse when MTX treatment was discontinued after clinical remission was achieved. A relapse may occur owing to new developing synovial inflammation. On the other hand, the risk of relapse may be influenced by residual synovial inflammation, even in the absence of clinical signs, when MTX is discontinued. So far, a reliable marker for such non-apparent disease activity in JIA has not been found in a prospective follow up. Our results indicate that prolonged treatment with MTX does not improve the status of remission in general. Thus, prolonged treatment with MTX for all patients, as proposed by some authors, ${ }^{45}$ does not generally seem to be appropriate. It is more important to identify individual patients at special risk for relapse in whom withdrawal of MTX might be harmful.

MRP8/MRP14 are released by activated phagocytes upon contact with endothelial cells in inflamed tissue. ${ }^{10}{ }^{11}$ Their serum concentrations correlate well with local inflammation. In our study MRP8/MRP14 serum concentrations decreased significantly in response to effective treatment with MTX. However, individual differences in MRP8/MRPI4 serum levels in inactive JIA point to the fact that a group of patients who are considered to be in remission according to clinical and routinely used laboratory criteria may have undetected local disease activity. These patients would be at special risk for a clinically apparent relapse of JIA as is frequently seen after withdrawal of MTX treatment.

Comparing a subgroup of patients who relapsed with those who did not, we found significantly lower serum levels of MRP8/MRP14 for the latter group. Thus, raised MRP8/ MRP14 serum levels point to patients with clinically undetectable local synovial inflammation for whom prolonged treatment with MTX will be beneficial. Taking into account the high pre-test probability of $50 \%$ for a relapse after discontinuation of MTX treatment, a likelihood ratio of 4.6 results in a substantial shift of the post-test probability to about $85 \%$ in the presence of high MRP8/MRP14 levels. ${ }^{14}$

Although our study group is relatively small these data demonstrate that MRP8/MRP14 are markers for clinically non-apparent disease activity. Further prospective studies have to prove that MRP8/MRP14 serum levels may be used to guide anti-inflammatory treatment in JIA. So far, the impact of the time point of MTX discontinuation on the risk for relapses has not been studied systematically. We cannot exclude the possibility that reasons related to patient characteristics influenced the decision for stopping MTX earlier or later, and that this might have influenced the subsequent occurrence of flares. Therefore, a controlled randomised study will be necessary to analyse if treatment with MTX can be safely stopped once individual patients have reached a status of remission without signs of residual synovial inflammation.

\section{ACKNOWLEDGEMENTS}

We thank Heike Harter for excellent technical assistance.

\section{Authors' affiliations}

D Foell, M Frosch, A Schulze zur Wiesch, J Roth, Department of

Paediatrics, University of Muenster, Albert-Schweitzer-Str 33, D-48149

Muenster, Germany

T Vogl, C Sorg, Institute of Experimental Dermatology, University of Muenster, Von-Esmarch-Str 58, D-48149 Muenster, Germany

Correspondence to: Dr D Foell; dfoell@uni-muenster.de

Accepted 20 May 2003

\section{REFERENCES}

1 Wallace CA. The use of methotrexate in childhood rheumatic diseases. Arthritis Rheum 1998;41:381-91.

2 Giannini EH, Brewer EJ, Kuzmina N, Shaikov A, Maximov A, Vorontsov I, et al. Methotrexate in resistant juvenile rheumatoid. Results of the USA-USSR double-controlled trial. N Engl J Med 1992;326:1043-9.

3 Woo P, Southwood TR, Prieur AM, Dore CJ, Grainger J, David J, et al. Randomized, placebo-controlled, crossover trial of low-dose oral methotrexate in children with extended oligoarticular or systemic arthritis. Arthritis Rheum 2000;43:1849-57.

4 Ravelli A, Viola S, Ramenghi B, Aramini L, Ruperto N, Martini A. Frequency of relapse after discontinuation of methotrexate therapy for clinical remission in juvenile rheumatoid arthritis. J Rheumatol 1995;22:1574-6.

5 Gottlieb BS, Keenan GF, Lu T, llowite NT. Discontinuation of methotrexate treatment in juvenile rheumatoid arthritis. Pediatrics 1997; 100:994-7.

6 Pinals RS, Masi AT, Larsen RA, and the subcommittee for Criteria of Remission in Rheumatoid Arthritis of the American Rheumatism Association Diagnostic and Therapeutic Criteria Committee. Preliminary criteria for clinical remission in rheumatoid arthritis. Arthritis Rheum 1981;24:1308-15.

7 Fink CH, Baum J, Bhettay E, Goldenberg J, He X, Maldonado-Coco J, et al. Proposal for the development of classification criteria for idiopathic arthritides of childhood. J Rheumatol 1995;22:1566-9.

8 Ruperto N, Ravelli A, Falcini F, Lepore L, De Sanctis R, Zulian F, et al. Performance of the preliminary definition of improvement in juvenile chronic arthritis patients treated with methotrexate. Ann Rheum Dis 1998:57:38-41.

9 Giannini EH, Ruperto N, Ravelli A, Lovell DJ, Felson DT, Martini A. Preliminary definition of improvement in juvenile arthritis. Arthritis Rheum 1997; 40:1202-9

10 Youssef P, Roth J, Frosch M, Costello P, FitzGerald O, Sorg C, et al. Expression of myeloid related proteins (MRP) 8 and 14 and the MRP8/14 heterodimer in rheumatoid arthritis synovial membrane. J Rheumatol 1999;26:2523-8.

11 Frosch M, Strey A, Vogl T, Wulffraat NM, Kuis W, Sunderkotter C, et al. Myeloid-related proteins 8 and 14 are specifically secreted during interaction of phagocytes and activated endothelium and are useful markers for monitoring disease activity in pauciarticular-onset juvenile rheumatoid arthritis. Arthritis Rheum 2000;43:628-37.

12 Petty RE, Southwood TR, Baum J, Bhettay E, Glass DN, Manners P, et al. Revision of the proposed classification criteria for juvenile idiopathic arthritis: Durban, 1997. J Rheumatol 1998;25:1991-4.

13 Davidson J. Juvenile idiopathic arthritis: a clinical overview. Eur J Radiol 2000;33:128-34.

14 American College of Rheumatology Ad Hoc Committee on Imunologic Testing Guidelines. Guidelines for immunologic laboratory testing in the rheumatic diseases: an introduction. Arthritis Rheum 2002;47:429-33.

15 Zweig MH, Campbell G. Receiver-operating characteristic (ROC) plots: a fundamental evaluation tool in clinical medicine. Clin Chem 1993;39:561-77. 